\title{
ASSERTING CATALOGERS' PLACE IN THE “VALUE OF LIBRARIES” CONVERSATION
}

\author{
Juliya Borie \\ Cataloguing Librarian \\ University of Toronto, Robarts Library \\ juliya.borie@utoronto.ca
}

Kate MacDonald

Cataloguing \& Digital Services Librarian

University of Toronto, Trinity College, John W. Graham Library

kate.macdonald@utoronto.ca

Elisa Sze

Librarian, Collections \& Public Services

University of Toronto, Faculty of Information (iSchool), Inforum

elisa.sze@utoronto.ca

\section{This post-print version of the original article was prepared by the authors on June 1, 2018.}

The original article was published in 2015, in Cataloging \& Classification Quarterly, Volume 53, Issue 3-4: Reshaping the Library Catalog: Selected Papers from the International Conference FSR2014 (Rome, February 27-28, 2014)

https://doi-org.myaccess.library.utoronto.ca/10.1080/01639374.2015.1007543 
Acknowledgement

A prototype of this paper was presented by the authors at Faster, Smarter, Richer: Reshaping the Library Catalogue, International Conference, in Rome in February 2014, under the title "Asserting our place in the 'value of libraries' conversation: the evolving role and future of cataloguing.”

http://eprints.rclis.org/22758/

The authors wish to thank Lynne Howarth at the University of Toronto for her feedback on an earlier draft, which resulted in the current manuscript.

1 


\title{
Asserting Catalogers' Place in the "Value of Libraries" Conversation
}

\author{
Abstract \\ Catalogers have a unique challenge to overcome in demonstrating the value of their services: the better \\ they are at performing their work—-making collections accessible and enabling user discovery—the more \\ invisible their efforts are to users and administrators. Catalogers must participate more actively in the \\ broader discussion and demonstration of library value undertaken by their colleagues, but to do so \\ requires a framework and a common vocabulary shared by non-catalogers.
}

\section{Introduction}

In 2010, the Task Force on Cost/Value Assessment of Bibliographic Control, sponsored by the Heads of Technical Services in Large Research Libraries Interest Group (the “Big Heads”), published a report that identified untapped opportunities for libraries to gather information on the value of bibliographic data production. ${ }^{1}$ Providing a research agenda for the cataloging community, the Task Force report was part of a larger movement called the "Year of Cataloguing Research," introduced by the Council of the American Library Association’s “Resolution Declaring and Promoting 2010 as the Year of Cataloging Research” in recognition of the "organization of information, including cataloging and metadata creation” as “a core function of the library profession.”2 Within the report, the Task Force indicated the significant challenge of their charge, given “the larger cultural context of the profession's inability to articulate value and, until recently, not being asked to do so in measured ways.”3

Since 2010, in addition to the Task Force report, a number of articles have been published asserting the need to communicate the value of academic libraries more effectively by providing evidence of outcomes related to user experience, an area that has been difficult to assess in respect to cataloging. ${ }^{4}$ For catalogers, this may lead to the question: where should their work — that is to say, descriptive cataloguing, subject analysis, classification, access point creation, authority control and production of 
metadata, carried out in order to facilitate the discovery of information-fit into the larger discourse on the value of academic libraries? To answer this question, this paper analyzes various frameworks for assessing areas of library service value; derives a unified model for analyzing the value of cataloguing that incorporates the research agenda of the Task Force report into the frameworks for assessing areas of library service value; and maps recent developments in cataloging and research undertaken in academic libraries, as described in the published literature, onto this unified model. Our goal is to assist catalogers in placing their work within the larger conversation of library value, and in doing so, advocate for cataloging's future within the academic institution.

\section{What Is the "Value of Academic Libraries" Conversation?}

As the foundation of our analysis of the "value of academic libraries" conversation, we specifically examined The Value of Academic and Research Libraries, by Oakleaf for U.S.-based Association of College and Research Libraries (ACRL); ${ }^{5}$ National Statistical and Values Profile of Canadian Libraries: Report to CLA Executive Council, by Schrader and Brundin on behalf of the Canadian Library Association (CLA); ${ }^{6}$ and The Value of Libraries for Research and Researchers, by Research Information Network and Research Libraries UK (RLUK). ${ }^{7}$ Key to our selection was that as library advocacy organizations, ACRL, CLA and RLUK produced the reports to generate a dialogue on the value of libraries throughout the library community. For these organizations, the discussions on value build on two underlying principles: one, that there is a pressing need to advocate more effectively for the ongoing relevance of libraries to their institutions and beyond; and two, in order to accomplish this, libraries must re-evaluate traditional measures of value that are not sophisticated enough to capture the impact of library services.

\section{Challenges}

One of the key assertions in the "value of libraries" conversation across the ACRL, CLA and RLUK reports is that academic libraries are at a critical juncture due to external and internal pressures. ${ }^{8}$ 
Changing technology in a networked society is a major factor driving the examination of libraries and value, ${ }^{9}$ as well as budgetary concerns that affect all library sectors. Within the academic sphere, the commodification of higher education - that is, the perception of universities and other higher education institutions as producers of commodities such as employable students or marketable research—has increased the requirement for these institutions to provide evidence of value to stakeholders. This marketization of education in turn requires academic libraries to justify their contribution to the larger academic institution. ${ }^{10}$ The RLUK report points out the implications of technological change and tightened budgets for academic libraries: with the increasing prevalence of remote access to research materials, future academic administrators will not necessarily associate the library with being the provider of information resources. ${ }^{11}$

\section{Articulating Value}

The second, and most significant issue in the discussion of "the value of libraries", is the difficulty in defining "value" and its relationship to "impact" within the library context. It is worth noting the distinction between the concepts. While not formally defined, the term "impact" is used in the ACRL, CLA and RLUK reports to refer to the intangible or tangible end result that individuals, institutions or society experience as a consequence of an existing service. Moreover, "impact” is discussed as evidence of "value.” A common challenge cited in the reports is determining whether value should be assessed by gathering data related to concrete evidence, such as cost, or by measuring abstract impacts such as prestige or user satisfaction. To address this issue, ACRL, CLA, and RLUK underscore the importance of assessing value by incorporating measures of both aspects. RLUK for instance presents value as "the direct and indirect benefits of libraries, actual or perceived." ${ }^{12}$ To distinguish the difference, RLUK suggests visualizing the "direct”, or quantifiable, benefits as those services or products that researchers derive from the library, such as journal access, while indirect, or qualitative, benefits could be exemplified by the library's contribution to the research profile of their home institutions. ${ }^{13}$ CLA recommends that libraries adopt common industry-wide operational definitions of value and 
methodologies that include return-on-investment (ROI) in conjunction with “value propositions”, or stories of user experience, that illustrate the impact of library services. ${ }^{14}$ ACRL provides specific operational definitions of value in five main categories: frequency of use, ROI, commodity production, creating value with end users, and finally, comparing competing alternatives. However, ACRL suggests that of the five, library stakeholders are most concerned with financial value and impact value, which is where libraries should focus their efforts when collecting data. ${ }^{15}$ The fundamental message from the three reports is that the traditional approach used by academic libraries to track and collect input-related data, such as circulation statistics, fails to illuminate the impact on the end user, and that libraries must develop methodologies that can capture the complexities of library value.

\section{The Literature on "the Value of Cataloging"}

The strategic reports by ACRL, CLA, and RLUK discussed above provide operational definitions of value and strategies to assess the value of library services relative to user outcomes. However, they tend to provide examples of how operational definitions of value can be applied to the assessment of services traditionally considered to be public facing, such as information literacy programs. ${ }^{16}$ Because cataloging occurs behind the scenes, it is not necessarily conceptualized as a public service, even within libraries, though ALCTS’statement in “The Value of Cataloging Librarians,” declares “cataloging librarianship is, at its heart, about service." ${ }^{17}$ However, as suggested by Intner, of all types of librarians, catalogers have traditionally been the least likely to successfully convey information about the value of the service they contribute to libraries. ${ }^{18}$ Before examining what catalogers should be communicating about their work, it is necessary to identify articles in the published literature since 2000 that have already explicitly considered the question of how to demonstrate the value of cataloguing to libraries as a whole. While we aimed to focus primarily on academic libraries, we expanded our search to the broader library environment to include directly relevant articles. And, although catalogers contribute to informal avenues of discussion on the value of cataloguing and its relationship to advocacy through mailing lists and blogs, at this stage, examining the informal publications on the value of cataloging was beyond our scope. ${ }^{19}$ 


\section{Inadequate Research on Cataloging}

Authors often cite the lack of research into cataloging and bibliographic control substantiated by assessment methodologies as a reason that few solid data exist about the value of cataloging to libraries. Without this foundation, it is difficult for catalogers to undertake new research. The designation of 2010 as the "Year of Cataloging Research," ${ }^{20}$ was the Council of the ALA's attempt to encourage more rigorous scholarship on bibliographic control and sharing of research practices and data. ${ }^{21}$ Two members of the previously mentioned "Big Heads" Task Force, Stahlberg and Cronin provide a historical review of cataloging and assessment literature for the report. They found that since the early $20^{\text {th }}$ century, there has been no shortage of published literature attempting to assess cataloguing by using cost/benefit analysis that incorporates factors such as staff time, per unit cost of copy cataloging and other inputs; however, assessment measures that encompass cost, value and benefit together are more rare. ${ }^{22}$

Besides the lack of research completed to date, there is another question of whether the cataloging research that has been undertaken has examined the right issues to generate data for advocacy. In Roeder's editorial on the "Year of Cataloging Research,” while not academic library specific, he suggests that catalogers should change the focus of cataloging research rather than merely increasing research output on cataloging. He believes that catalogers must stop defining the function of their work by formats and standards that may be obsolete in the near future, or risk being shut out of the conversation on the future of bibliographic control. ${ }^{23}$ CannCasciato offers a similar view: that the objective of cataloging is commonly, albeit mistakenly, perceived to be the production of bibliographic records, the most tangible and easily quantifiable results of the work. For CannCasciato, this perception obscures the true purpose of cataloging - to provide a surrogate for reference interactions - and leads to the over-emphasis on assessing the cost of cataloging relative to productivity instead of the benefits to users. ${ }^{24}$ Miksa's study on authority control provides a specific example how catalogers are not gathering data that is fundamental to explicating the value of the work. In her survey of two Texas library systems, she found that libraries did not actively collect authority control data, and in some cases, the libraries surveyed rarely performed authority database maintenance, probably to save on costs. She speculates that catalogers themselves 
struggle to articulate to administrators the importance of authority control for information discovery, and therefore, are unable to prove its impact on users. ${ }^{25}$ Carlyle agrees that there is an idea among noncataloging librarians that cataloging is expensive; but without better research into the impact on end users, it is difficult to refute or reassess whether current practices are worth the investment. ${ }^{26}$

Other researchers have provided suggestions of how to shift the research focus of cataloging from the typical measures of quantity. Paiste uses a theoretical framework based on Deming's Total Quality Management that looks specifically at how the quality of cataloging provides value to academic libraries. She suggests that cataloging assessment should incorporate more measures of quality to understand how to meet user needs rather than focussing primarily on measures of accuracy. ${ }^{27}$ In a more recent article on cataloging quality, De Fino and Wang's survey of New Jersey academic library cataloging departments found that the majority of libraries still continued to collect cataloging statistics, or the number of records produced, to demonstrate value. Based on the findings, De Fino and Wang perceive that there is still a strong tendency across technical services departments to gather easily tracked and quantifiable data about cataloging in the same manner as has always been done by relying on productivity measures. They also agree with Paiste that assessing the quality of records, and more specifically looking at how record quality is linked to increased discovery of library information, would provide greater insight into the value of cataloging. ${ }^{28}$ Overall, we found that technical services literature in general includes many articles on cataloging innovation and measurement of productivity and cost, but few engage with the topic of cataloging within the broader "value of libraries" discussion, particularly in academic libraries, which has implications in terms of explicating how cataloging is a valuable service to libraries.

\section{Re-situating the "Value of Cataloging" Discussion within a Synthesized}

\section{“Value of Academic Libraries” Framework}

Much like the ACRL, CLA, and RLUK reports in their call for more rigorous assessment of academic libraries, the "Big Heads” Task Force ${ }^{29}$ encourages the cataloguing community to develop more rigorous assessment of bibliographic control, in pursuit of demonstrating value to stakeholders and administrators. 
In doing so, the Task Force shares some similarities with the other reports. Despite the Task Force's specialized focus on bibliographic control, as opposed to library services at large, like the other reports, the Task Force acknowledges the complex, multi-faceted interpretations of the term "value.” It reports difficulties in defining "high-value” versus "low-value” bibliographic elements and activities due to the dearth of research studies into how users employ library- and non-library-generated metadata. ${ }^{30}$ This theme (i.e., the shortage of research) is reiterated in the ACRL and CLA reports. The Task Force further states that it wrestled with the notion of a universally comprehensible definition for "value”, or an “industry standard” for catalogue records and metadata, even when such a definition is restricted to the context of bibliographic control, because metadata consumers are diverse groups of users with their own needs for quality. ${ }^{31}$

As a result, the Task Force suggests a framework for future research organized around seven operational definitions of the value of bibliographic control: discovery success, use, display understanding, interoperability with other systems, support of FRBR user tasks, throughput or timeliness, and support of library administrative goals. ${ }^{32}$ Presented alongside each of these seven operational definitions of value are the Task Force’s proposed research methodologies. They include: user log analysis to compare the usefulness of MARC versus non-MARC bibliographic systems for discovery and retrieval of data; ${ }^{33}$ user behaviour studies; ${ }^{34}$ analysis of circulation statistics or usage of material before and after full cataloguing; ${ }^{35}$ user surveys and focus groups to find out which bibliographic elements users actually use or pay attention to; ${ }^{36}$ research on the extent to which non-MARC metadata (more specifically, ONIX data) have been adopted across the bibliographic community; ${ }^{37}$ and studies to determine the amount of library-generated metadata that is being used "outside the library ecosystem." 38 The Task Force's operational definitions of value, particularly, the terminology used and the types of studies proposed, either focus on functions requiring cataloging-specific knowledge, or target specific constituents of the bibliographic community such as information systems specialists, user experience designers, and user behaviour researchers. This level of functional specialization makes it challenging on the surface to map the Task Force’s discussion of "the value of cataloging” against the 
broader framework of "the value of the academic library," modelled by the ACRL, CLA, and RLUK reports. Even where concepts of value appear in all reports—namely, the notion of "use" and "support of library administrative goals"- the authors engage with the concepts differently. ACRL and RLUK, for instance, would suggest that library administrative goals refer to higher-level institutional strategic goals such as improving overall faculty and student experience, improving recruitment of faculty and students, and advancing institutional prestige. In contrast, the Task Force report defines administrative goals functionally in terms of other staff members' use of cataloging output in the course of their own work. Whereas ACRL discusses "use” in terms of correlating user behaviour with specific institutional outcomes such as student enrolment and success, or faculty teaching and research productivity, the Task Force focuses on "use" simply as use. Figure 1 below is a visual representation of how the ACRL, CLA, RLUK, and Task Force reports approach the concept of "value".

9 
FIGURE 1 Definitions of "value” within the library context vs. definition of "value” within bibliographic control.

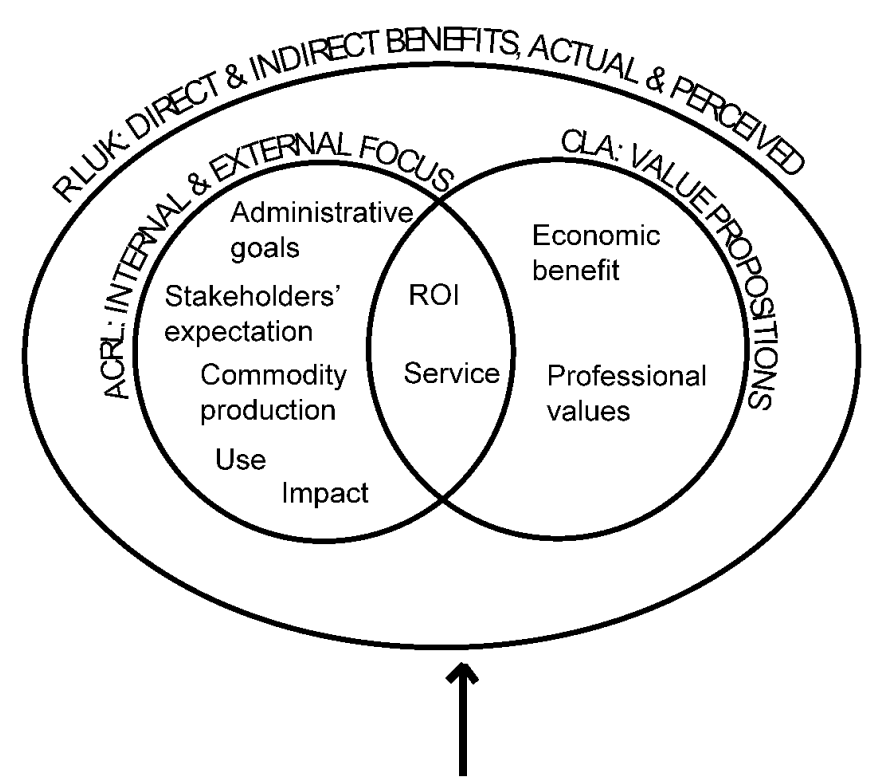

TASK FORCE: 7 OPERATIONAL DEFINITIONS

OF BIBLIOGRAPHIC CONTROL

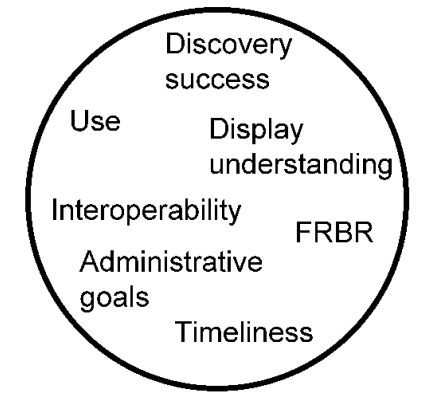

While the Task Force's operational definitions of value and proposed methodologies for developing assessment metrics encourages catalogers to re-examine the functions of their work, a crucial bridge between the assessment of cataloguing and "the value of libraries" discussion appears to be missing. Catalogers advocate more convincingly for the value of their contributions to the library ecosystem when they focus not only on assessing the immediate output of their production, as pointed out 
earlier by CannCasciato and Roeder, but when they relate their services (i.e., enabling discovery) back to their impact on broader institutional strategic goals like research productivity, student success, and teaching.

As an example of this bridging, the Task Force's proposals can be re-read from the perspective of institutional and user impact. Research into “discovery success”, “use”, and "support of FRBR user tasks”, cataloguers (and libraries) would include articulating the relationship between, on the one hand, discovery and use of information, and, on the other, the enhancement of faculty teaching, research, and student academic achievement. As strategic institutional goals highlighted by ACRL, faculty and student achievement would be well worth demonstrating by all units and departments within the academic library, regardless of their functions. In the Task Force’s proposal for more research into “display understanding”, cataloguers can articulate how the design and display of bibliographic data contributes to the student and faculty experience at their academic institution, as well as enhance their research productivity. In examining the interoperability of bibliographic data with non-library bibliographic systems, and also adoption of library-generated metadata by non-library organizations, cataloguers could draw out observations regarding potential contributions to the academic institution's reputation and prestige.

The following table is our synthesis of the "value of academic libraries” framework, positioning the "value of cataloging" directly within the context of the same conversation. 
TABLE 1 Framework for Understanding Areas of Library Service Value

\begin{tabular}{|c|c|c|c|}
\hline $\begin{array}{l}\text { Synthesis } \\
\text { of ACRL, } \\
\text { CLA \& } \\
\text { RIN/ } \\
\text { RLUK }\end{array}$ & Student Experience & Faculty Experience & Administrative Goals \\
\hline Details & $\begin{array}{l}\text { Library services directly } \\
\text { and indirectly impact: } \\
\text { - Student recruitment } \\
\text { - Student retention } \\
\text { - Learning experience } \\
\text { - Student achievement } \\
\text { on major tests and } \\
\text { - } \text { assignments } \\
\text { Graduation }\end{array}$ & $\begin{array}{l}\text { Library services directly } \\
\text { and indirectly impact: } \\
\text { - Faculty recruitment } \\
\text { - Research productivity } \\
\text { - Grants applied and } \\
\text { obtained } \\
\text { - Teaching }\end{array}$ & $\begin{array}{l}\text { Institutional reputation } \\
\text { and prestige result from: } \\
\text { - } \text { Institutional rankings } \\
\text { - Student \& faculty } \\
\text { success } \\
\text { - } \text { Preservation of } \\
\text { scholarly documentary } \\
\text { history } \\
\text { Leading to: } \\
\text { - } \text { Advancement of } \\
\text { positive alumni [and } \\
\text { donor] relations } \\
\text { - Recruitment and } \\
\text { retention of high } \\
\text { performing students } \\
\text { and faculty } \\
\text { - More funding }\end{array}$ \\
\hline $\begin{array}{l}\text { How the } \\
\text { Task } \\
\text { Force's “7 } \\
\text { operational } \\
\text { definitions } \\
\text { of value” } \\
\text { fit within } \\
\text { the } \\
\text { synthesized } \\
\text { framework }\end{array}$ & $\begin{array}{l}\text { Students' learning } \\
\text { experience and } \\
\text { achievement are directly } \\
\text { and indirectly impacted } \\
\text { by cataloguers’ } \\
\text { contributions to: } \\
\text { - Discovery success (\#1) } \\
\text { - Use (\#2) } \\
\text { - Display understanding } \\
\text { (\#3) } \\
\text { - Ability to support } \\
\text { - FRBR user tasks (\#5) } \\
\text { Throughput/ } \\
\text { Timeliness (\#6) }\end{array}$ & $\begin{array}{l}\text { Faculty’s research and } \\
\text { teaching activities are } \\
\text { directly and indirectly } \\
\text { impacted by cataloguers' } \\
\text { contributions to: } \\
\text { - Discovery success (\#1) } \\
\text { - Use (\#2) } \\
\text { - Display understanding } \\
\text { (\#3) } \\
\text { - Ability to support } \\
\text { FRBR user tasks (\#5) } \\
\text { - Throughput/ } \\
\text { Timeliness (\#6) }\end{array}$ & $\begin{array}{l}\text { Interoperability of library- } \\
\text { generated data (\#4) can } \\
\text { advance public discovery } \\
\text { and awareness of } \\
\text { institutional collections, } \\
\text { thereby enhancing } \\
\text { institutional prestige. } \\
\text { By supporting students’ } \\
\text { and faculty’s resource and } \\
\text { discovery needs, } \\
\text { cataloguers support } \\
\text { administrative goals (\#7). }\end{array}$ \\
\hline
\end{tabular}


Catalogers have additional opportunities to demonstrate their value by carving a role for themselves in the research agenda presented by the "value of academic libraries" reports. For instance, as pointed out by RLUK, academic libraries today continue to exist in an environment in which research institutions see large library collections as a source of pride, and evidence of scholarly reputation and prestige ${ }^{39}$ However, the fact that such vast collections are cataloged is often taken for granted, with catalogers failing to seize the opportunity to articulate their role in making these collections visible. Many researchers already rely on library assistance when conducting literature reviews as part of grant projects, yet this library service should be recognized in grant applications as a special service, and not simply an overhead cost. ${ }^{40}$ Going a step further, if the institutional culture encourages faculty to factor library services into grant budgets, valuable correlations could be drawn by looking at the success rate of grant applications that require services such as the cataloging of special collections. ${ }^{41}$ The report additionally suggests analyzing the "surrogates for library impact", such as the quantity of faculty publications and patents listed in CVs and research profiles. ${ }^{42}$ Cataloging data could be tied into this analysis.

\section{Rediscovering Value}

To help researchers sift through the deluge of information and navigate the relationships between resources, the library community has been developing both new conceptual models as well as new applications to enable different modes of information discovery. This section of the paper explores how recent developments along with new uses of core cataloging functions, such as authority control, can be viewed through the lens of the reconfigured "value of cataloging” framework, and repositions the work and expertise of catalogers with advocacy in mind.

\section{Harnessing a Core Cataloging Function for Discovery Success \& Use}

As the magnitude of available scholarly resources has increased, the value of library collections is defined not only by quantity and uniqueness, but by the ways in which libraries enable information discovery. ${ }^{43}$ In 
this context, authority data, compiled collaboratively by cataloguers over a long span of time, can be used to create pathways for discovery of resources. In a recent study, Gross, Taylor and Joudrey found that the presence of authorized subject headings in bibliographic records substantially improved discovery success for users. ${ }^{44}$ Through trustworthy authority records for authors, corporate bodies, works and subjects published as Linked data, user search and discovery of resources can be enhanced by way of better search relevancy, faceted navigation and serendipitous discovery of information resources. ${ }^{45}$ The W3C Library Linked Data Incubator Group indicates in their report that authority records could become a starting point for libraries' participation in the Semantic Web. ${ }^{46}$ The role of controlled vocabulary is further highlighted with the inclusion of Authorities as one of the four main classes of the Library of Congress's BIBFRAME Linked Data model. ${ }^{47}$ By expanding current authority control practices through the use of Linked Data principles in the form of Uniform Resource Identifiers (URIs), the value of authority records can be increased. In a Linked Data environment, authorities can function as effective and reliable identifiers, helping navigate relationships between entities and resources for users. While noting the important role of entities (people, places, concepts and events) in collections, Dempsey, Malpas and Lavoie indicate that their role in enhancing the reputation of institution is yet to be explored and quantified. ${ }^{48}$ To continue advocating for the existing and emerging value of authorities, cataloguers need to better articulate the value of authority control in the evolving library landscape that spans beyond the library catalogue.

\section{Improving Interoperability of Cataloging Data}

Many current Linked Data initiatives in libraries involve publishing value vocabularies, including authority data, Resource Description and Access (RDA) vocabularies as well as bibliographic data as Linked Data. As Bermès notes, the real added value of Linked Data might be in improved interoperability with other cultural heritage communities. ${ }^{49}$ Dunsire and Willer write that in a linked data environment, "the archive, library, and museum communities can focus on maintaining metadata unique to the needs of their members, such as provenance, availability, suitability, and context. Metadata of more general interest, such as label, format, associated places and events, will be accessible as linked data from other 
communities.”50 Increasingly, publishers are using Semantic Web technologies to publish their bibliographic data as Linked Data in RDF triples in order to help users contextualize and navigate their resources. ${ }^{51}$ As more stores of linked data become available, the potential to share and improve interoperability of data between various communities in a global information space becomes evident. ${ }^{52}$

\section{Enabling Discovery Success, Support of FRBR Tasks \& Support of Administrative Goals}

A recent example of Linked Data implementation by the Bibliothèque nationale de France (BnF) demonstrates the opportunities to improve user experience with Linked Data through its data.bnf.fr website. ${ }^{53}$ By using FRBR principles and disaggregating the component of the bibliographic data by publishing it as Linked Open Data in RDF format, the site provides a discovery interface that pulls together information on major authors, works and subjects, linking out to external data sets and displaying this data to user in novel ways. ${ }^{54}$ An assessment of the BnF Linked Data project indicates an enhanced discoverability, demonstrated by better ranking in search engines and increased use of digital collections of BnF. ${ }^{55}$ Arguably, this project is an example of how advancing discovery of research collections on the web can lead to enhanced institutional prestige. ${ }^{56}$

\section{Cataloging Data as Primary Source for Faculty Research}

Another possibility to rediscover value while supporting institutional goals includes using digital humanities applications to create new uses of the catalog data for scholarly research. While find-andretrieve has become a relatively simple task in the scholarly research process, developing new methods to situate and understand facts, concepts, and documents within the context of the larger body of information should be the next frontier. ${ }^{57}$ An example of this kind of new use of catalog data is illustrated by the work of Alexopoulos and Cohen, economics scholars who analyzed subject headings in catalog MARC records to study patterns of technical change over the course of the last century. ${ }^{58}$ Harnessing opportunities for digital humanities scholarship might further highlight the value of cataloging data, leading to new discoveries. 


\section{Catalogers Directly Supporting Administrative \& Academic Success Programs}

At a time of changing discovery environments and evolving cataloguing practice, catalogers’ visibility can be enhanced through possible collaborations with other units in order to create and assess value. This includes exploiting library systems and metadata knowledge for cross-departmental projects, ${ }^{59}$ extending the public service dimension of cataloguers' work through building programs and collections, ${ }^{60}$ and coteaching information literacy classes. ${ }^{61}$ It is essential for catalogers to show adaptability, maintaining high standards of quality while exploring new ways of making collections visible on the web for research, learning and teaching.

\section{Conclusion}

Despite many innovations in cataloging, such as those discussed in this paper, more must be done not only to measure the impact of these innovations on users, but to relate these back to the context of the “value of academic libraries” discussion. We have attempted to contribute to future research by mapping what the "Big Heads" Task Force considers to be the seven operational definitions of value within bibliographic control against the broader picture of academic library value. We have also attempted to show how extending the research agenda set by the broader "value of academic libraries" discussion to include catalogers and cataloging data can position the value of cataloging within the academic library.

Underlying the discussions of library value that we examined is the recognition that stronger advocacy measures are necessary in order for libraries to maintain their standing within the academic institution of the future. Similarly, catalogers' research agenda must complement a more activist approach to the values conversation, using terms that can be understood by a broader institutional audience.

Catalogers must learn to communicate in the language of administrators and users, using approaches of broad appeal that speak within and beyond the cataloging community. Educating stakeholders on what cataloguers do is not enough in the current climate; evidence-based arguments must be made, demonstrating the direct contribution of cataloging services and innovations to institutional-wide goals such as impact on users, institutional reputation and prestige. As catalogers, it is vital that we create not 
only a body of evidence to support our position within the "value of academic libraries" conversation, but to articulate explicitly that we are participating in the same conversation as the rest of the academic institution.

\footnotetext{
${ }^{1}$ Task Force on Cost/Value Assessment of Bibliographic Control, Final Report of the Task Force on Cost/Value Assessment of Bibliographic Control, Submitted to the Heads of Technical Services in Large Research Libraries Interest Group (Washington, D.C.: ALA Annual Conference, June 18, 2010), http://connect.ala.org/files/7981/costvaluetaskforcereport2010_06_18_pdf_77542.pdf.

${ }^{2}$ Council of the American Library Association, "Resolution Declaring and Promoting 2010 as the Year of Cataloging Research” (ALA, January 17, 2010), 1, http://www.ala.org/aboutala/sites/ala.org.aboutala/files/content/governance/council/council_documents/2 010mw_concil_docus/cd34_catalogingresea.pdf.

${ }^{3}$ Task Force on Cost/Value Assessment of Bibliographic Control, Final Report of the Task Force on Cost/Value Assessment of Bibliographic Control, 2.
}

${ }^{4}$ Some recent examples include: Claire Creaser and Valérie Spezi, Working Together: Evolving Value for Academic Libraries (Loughborough University, June 2012), http://libraryvalue.wordpress.com/report/; Carol Tenopir, “Beyond Usage: Measuring Library Outcomes and Value,” Library Management 33, no. 1/2 (December 30, 2011): 5-13, doi:10.1108/01435121211203275; Danuta A. Nitecki, “Exploring the Cause and Effect of Library Value,” Performance Measurement and Metrics 14, no. 1 (January 1, 2013): 17-24; J. Stephen Town and Martha Kyrillidou, “Developing a Values Scorecard,” Performance Measurement and Metrics 14, no. 1 (January 1, 2013): 7-16.

${ }^{5}$ Megan J. Oakleaf, The Value of Academic Libraries: A Comprehensive Research Review and Report (Chicago, IL: Association of College and Research Libraries, 2010), http://www.ala.org/ala/mgrps/divs/acrl/issues/value/val_report.pdf. 
${ }^{6}$ Alvin Schrader and Michael Brundin, National Statistical and Values Profile of Canadian Libraries: Report to CLA Executive Council (Canadian Library Association, 2012), http://www.cla.ca/AM/Template.cfm?Section=Advocacy\&Template=/CM/ContentDisplay.cfm\&ContentI $\mathrm{D}=13783$. The authors selected this CLA report because it partly addresses academic libraries in Canada, whereas the Canadian Association of Research Libraries has not, to date, produced a report on the value of academic libraries.

${ }^{7}$ Research Information Network and Research Libraries UK, The Value of Libraries for Research and Researchers (London: RIN \& RLUK, March 2011), http://www.rin.ac.uk/our-work/using-and-accessinginformation-resources/value-libraries-research-and-researchers.

${ }^{8}$ Oakleaf, The Value of Academic Libraries, 11; Schrader and Brundin, National Statistical and Values Profile of Canadian Libraries: Report to CLA Executive Council, 1; Research Information Network and Research Libraries UK, The Value of Libraries for Research and Researchers, 8.

${ }^{9}$ OCLC's Perceptions of Libraries oft-repeated finding that the vast majority of American information seekers begin information searches on search engines and not library websites, is one of the statistics pointed to as critical evidence of the need for libraries to adapt to user expectations. Online Computer Library Center OCLC, Perceptions of Libraries, 2010: Context and Community (Dublin, OH: OCLC, 2011), 33, http://www.oclc.org/reports/2010perceptions/2010perceptions_all.pdf.

${ }^{10}$ Oakleaf, The Value of Academic Libraries, 11.

${ }^{11}$ Research Information Network and Research Libraries UK, The Value of Libraries for Research and Researchers, 14.

${ }^{12}$ Ibid., 11.

${ }^{13}$ Ibid.

${ }^{14}$ Schrader and Brundin, National Statistical and Values Profile of Canadian Libraries: Report to CLA Executive Council, 8.

${ }^{15}$ Oakleaf, The Value of Academic Libraries, 22. 
${ }^{16}$ Town and Kyrillidou suggest that the catalog is an intangible meta-asset developed to add value to tangible or physical assets of the library such as the collections, environments and services. Though metaassets represent a significant part of the overall value of academic libraries, due to the challenges in assessing their value, they are often left out of discussions of library value assessment. Town and Kyrillidou, “Developing a Values Scorecard,” 13.

${ }^{17}$ ALCTS, "Value of Cataloging Librarians," Association for Library Collections \& Technical Services, June 13, 2006, http://www.ala.org/alcts/resources/org/cat/catlibvalue.

${ }^{18}$ Sheila Intner, “Cataloger PR: is that an oxymoron,” Technicalities, 32, no. 3 (May/June, 2012), 12.

${ }^{19}$ Themes such as the value of cataloging and advocacy messaging appear from time to time on the Autocat mailing list and on cataloging blogs. For a selection of informal publications, see the following sources: James Weinheimer, “Respecting the Value of Cataloguing (\#176281),” Mailing list message, AutoCat, (January 4, 2013). Lynne Dyer, “The Role of the Cataloguer in the 21st Century,” High Visibility Cataloguing, accessed February 13, 2013, http://highvisibilitycataloguing.wordpress.com/professional-positive-advocacy/the-role-of-the-cataloguerin-the-21st-century/. Claire Sewell, "Librarian in Training: CIG 2012 - The Value of Cataloguing (Part Two),” Librarian in Training, September 16, 2012, http://www.librarianintraining.com/2012/09/cigvalue-of-cataloguing-part-two.html. Rachel, “The Value of Cataloguing: CILIP Cataloguing and Indexing Group Conference 2012,” The Toast in the Machine, accessed January 18, 2014, http://playforth.wordpress.com/2012/09/12/the-value-of-cataloguing-cilip-cataloguing-and-indexinggroup-conference-2012/.

20 “News,” ALCTS Newsletter Online (ANO) 20, no. 4 (December 2009), http://www.ala.org/alcts/ano/v20/n4/nws/alcts\#1.

${ }^{21}$ Jimmie Lundgren, “2010, Year of Cataloging Research in Review,” Bulletin of the American Society for Information Science and Technology (Online) 37, no. 5 (July 2011): 36-40; Library of Congress. Working Group on Bibliographic Control, On the Record: Report of the Library of Congress Working 
Group on the Future of Bibliographic Control, 2008, www.loc.gov/bibliographic-future/news/lcwgontherecord-jan08-final.pdf.

${ }^{22}$ Christopher Cronin and Erin Stalberg, “Assessing the Cost and Value of Bibliographic Control,” Library Resources \& Technical Services 55, no. 3 (July 2011): 124+.

${ }^{23}$ Randy Roeder, “A Year of Cataloging Research,” Library Resources \& Technical Services 54, no. 1 (January 2010): 2-3.

${ }^{24}$ Daniel CannCasciato, “An Essay on Cataloging,” Library Philosophy and Practice, November 2010, http://www.webpages.uidaho.edu/ mbolin/lpp2010.htm.

${ }^{25}$ Shawne Miksa, "You Need My Metadata: Demonstrating the Value of Library Cataloging,” Journal of Library Metadata 8, no. 1 (2008): 23-35.

${ }^{26}$ Allyson Carlyle, “Invited Editorial: Announcing 2010, Year of Cataloging Research,” Cataloging \& Classification Quarterly 47, no. 8 (October 9, 2009): 687-90.

${ }^{27}$ Marsha Starr Paiste, “Defining and Achieving Quality in Cataloging in Academic Libraries: A Literature Review,” Library Collections, Acquisitions, and Technical Services 27, no. 3 (2003): 327-38.

${ }^{28}$ Melissa De Fino and Jianrong Wang, “Counting Cataloging: Moving Beyond Statistics to Measure the Value of Cataloging,” LIBRES: Library and Information Science Research Electronic Journal 22, no. 1 (March 2012): 1-9.

${ }^{29}$ Task Force on Cost/Value Assessment of Bibliographic Control, Final Report of the Task Force on Cost/Value Assessment of Bibliographic Control.

${ }^{30}$ Ibid., 5.

${ }^{31}$ Ibid., 6.

${ }^{32}$ Ibid., 2.

${ }^{33}$ Ibid., 7.

${ }^{34}$ Ibid.

${ }^{35}$ Ibid., 8.

${ }^{36}$ Ibid., 8-9. 
${ }^{37}$ Ibid., 10.

${ }^{38}$ Ibid., 11.

${ }^{39}$ Research Information Network and Research Libraries UK, The Value of Libraries for Research and Researchers, 20.

${ }^{40}$ Ibid., 16.

${ }^{41}$ Ibid., 25.

${ }^{42}$ Ibid., 63.

${ }^{43}$ Tony Horava, “Challenges and Possibilities for Collection Management in a Digital Age.” Library Resources \& Technical Services 54, no. 3 (2012): 146.

${ }^{44}$ Ibid., 30.

${ }^{45}$ Getaneh Alemu, Brett Stevens, Penny Ross and Jane Chandler, "Linked Data for libraries: Benefits of a conceptual shift from library-specific record structures to RDF-based data models.” New Library World, 113, no.11/12 (2012): 549-570, doi: 10.1108/03074801211282920.

${ }^{46}$ W3C Incubator Group, “Library Linked Data Incubator Group Final Report,” W3C, (October 25, 2011), www.w3.org/2005/Incubator/lld/XGR-lld-20111025/.

${ }^{47}$ Angela Kroeger, "The Road to BIBFRAME: the Evolution of the Idea of Bibliographic Transition into a Post-MARC Future,” Cataloging \& Classification Quarterly 51, no. 8 (2013): 877.

${ }^{48}$ Lorcan Dempsey, Constance Malpas and Brian Lavoie, “Collection Directions: Some Reflections on the Future of Library Collections and Collecting,” portal: Libraries and the Academy, 14, no. 3 (July 2014): 412.

${ }^{49}$ Emmanuelle Bermès, “Enabling Your Catalog for the Semantic Web,” in Catalogue 2.0: The Future of the Library Catalogue, ed. Sally Chambers (Chicago: American Library Association, 2013), 117-42.

${ }^{50}$ Gordon Dunsire and Mirna Willer, “Initiatives to Make Standard Library Metadata Models and Structures Available to the Semantic Web.” World Library and Information Congress: 76th IFLA General Conference and Assembly, August 10-15, 2010, Gothenburg, Sweden, 12. http://www.ifla.org/files/hq/papers/ifla76/149-dunsire-en.pdf. 
${ }^{51}$ Nature Publishing Group, “Linked Data Platform,” Nature.com Developers, accessed June 3, 2014, http://www.nature.com/developers/documentation/linked-data-platform/.

${ }^{52}$ Lynne C. Howarth, “FRBR and Linked Data: Connecting FRBR and Linked Data,” Cataloging \& Classification Quarterly 50, no. 5-7 (2013): 769, 773.

${ }^{53}$ Bibliothèque nationale de France, “About Data.bnf.fr,” http://data.bnf.fr/about.

${ }^{54}$ Philip Evan Schreur, “The academy unbound: linked data as revolution,” Library Resources \&

Technical Services 56, no. 4 (October 2012): 232.

${ }^{55}$ Gildas Illien, “Are you ready to dive in? A case for Open Data in national libraries,” In World Library Information Congress, $78^{\text {th }}$ IFLA General Conference and Assembly (2012):7, http://conference.ifla.org/past-wlic/2012/181-illien-en.pdf.

${ }^{56}$ Stanford University Libraries. SPIRL 2013 prizes, http://library.stanford.edu/projects/stanford-prizeinnovation-research-libraries-spirl.

${ }^{57}$ Eric Lease Morgan, "Use and Understand: the Inclusion of Services Against Texts in Library Catalogs and “Discovery Systems,” Library Hi Tech 30, no. 1 (2012): 35-59, doi: 10.1108/07378831211213201. ${ }^{58}$ Michelle Alexopoulos and Jon Cohen, “Volumes of Evidence--Examining Technical Change in the Last Century through a New Lens,” Canadian Journal of Economics 44, no. 2 (May 2011): 413-50, doi:10.1111/j.1540-5982.2011.01639.x.

${ }^{59}$ Anne C. Elguindi and Alayne Mundt Sandler, “The ILS as Outreach: Cataloging Campus Partner Collections,” Cataloging \& Classification Quarterly 51, no. 1-3 (2013): 291-310, doi:10.1080/01639374.2012.722589; Anne Marie Taber and Mary Jane Conger, “Relevance Recognized: Value-Added Cataloging for Departmental and Digital Collections” 48, no. 6-7 (August 25, 2010): 585601.

${ }^{60}$ Mac Nelson, “The Cello Music Cataloger as Program Builder,” Cataloging \& Classification Quarterly 48 (2010): 634-644. 
${ }^{61}$ Carolyn J. McCallum and Bobbie L. Collins, “Enhancing the Information Literacy Classroom

Experience: A Cataloger and a Reference Librarian Team up to Deliver Library Instruction,” Library Collections, Acquisitions, and Technical Services 35, no. 1 (Spring 2011): 10-18.

23 